\title{
THE EFFECT OF INADEQUATE ACCESS TO POTABLE WATER ON THE HEALTH OF THE PEOPLE IN THE WA MUNICIPALITY OF GHANA
}

\author{
Ebenezer Nkrumah $^{1^{*}}$, Yaw Frimpong ${ }^{1}$, Adubofour Isaac ${ }^{2}$ \\ ${ }^{1}$ School of Management, Jiangsu University, Zhenjiang, P.R. China \\ ${ }^{2}$ School of Finance and Economics, Jiangsu University, Zhenjiang, P.R. China
}

"Correspondence: Ebenezer Nkrumah

Article DOI: https://doi.org/10.36713/epra8370

DOI No: $10.36713 /$ epra8370

\begin{abstract}
Accessibility to safe drinking water is regarded as a fundamental human right since it is essential to preserving healthy livelihoods and the basic human dignity of all human beings. The study examined the effect of inadequate potable water supply on the health of the people in the Wa Municipality of Ghana. Findings of the study revealed that water related diseases are very common in the municipality due to the inadequate supply of potable water. About $55 \%$ of respondents, mentioned schistosomiasis as the top disease burden in the area. Again, the analysis of data on water provision and accessibility in the study suggested that most of the residents of the Municipality precisely $69.2 \%$ covered distances more than the standard distance of $1 \mathrm{~km}$ stipulated by World Health Organization in search for potable water. The impacts of the time spent and distance traveled to acquire water in the Municipality were largely experienced by children and women, owing to the fact that in Ghana, water collection is considered to be the primary duty of children and women. Based on the findings the study recommends that more boreholes should be provided in the Wa Municipality to enable the residents have easy access to potable water supply.
\end{abstract}

KEYWORDS: Ghana, Wa Municipality, Potable water accessibility.

\section{INTRODUCTION}

A reasonable access to an acceptable amount of water from an upgraded source, such as a public standpipe, household connection, borehole, protected well, spring rainwater collection or protected well, (UNICEF/ WHO, 2017). According to WHO/UNICEF (2015), reasonable access is defined as "the availability of at least 20 liters per person per day from sources within one kilometer of the habitation. "The further definition of reasonable access where quality of water is given importance is a good measure since once a source of water has been provided quality is given more attention than quantity Chaplin, S. E. (1999). Water that can be given to the user and is safe for drinking, personal hygiene, food preparation, and washing is known as safe drinking (potable) water. At the point of supply to the users, the water should be able to meet the requisite (biological, chemical, and physical) quality criteria. As a result, safe drinking water is a relative phrase that is determined by a country's quality standards and guidelines; the requirements set for various quality metrics varies. The WHO standard differs from that of the United States, Canada, China, Japan, Ghana, the European Commission, South Africa, and the rest of the world. The term "safe" refers to a person's ability to withstand certain substances. Some Nations' clean drinking water may not be safe in Asian countries. Several African nations have already evolved resilience to water-borne illnesses. Access to adequate potable water is considered to be very critical prerequisite for improving health, however, most countries are faced with the plight of fetching water from various water sources which could be contaminated. Potable water scarcity has become a severe issue in the world, from a local to a global level, and has attracted a lot of attention (Volker, 2007).

Despite the fact that water covers three-quarters of the planet, it is nevertheless considered a limited resource in this world because only $1 \%$ of useable clean water is available for human consumption on a 
daily basis. According to the report by WHO and UNICEF through their Joint Monitoring Programme (JMP) for water supply and sanitation, about 2.3 billion people lack access to an improved drinking water. The report indicates that global access to safe drinking water over the past two decades has not been, this implies that the success of MDGs is even doubtful since most developing countries, particularly the poor still find it difficult to access safe drinking water. Access to potable drinking water is a serious issue in most Ghanaian communities of which Upper West is no exception. Quality health is a powerful tool for development and one of the strongest instruments for reducing poverty, gender inequality, mortality rate, promoting peace and stability in a country (Shedrack \& Nayebare, 2014). Quality health is a critical tool for breaking the cycle of poverty and yet most of the communities in Ghana lack access to potable water. Inadequate potable drinking water has serious effects on people health in Ghana. According to Ghana Government (2003) about $26 \%$ of Ghana's rural population does not have access to improved water; women and children usually bear primary responsibility for water collection. Available information shows that communities with adequate potable water supply are always healthy and strong and can get ample time for other development projects. In most studies, the problem of improved water and sanitation facilities is related to the rapid speed of urbanization and population increase (WHO \& UNICEF, 2006; Helena L. 2009; UN-Habitat, 2006). Urbanization and population rise are escalating the strains on trends and future in many countries of the globe, culminating in more residents living without access to safe drinking water (Hubbard et. al, 2011). Ghana has been urbanized, according to the Ghana Statistical Service (2010), signaling a need for municipal authorities to take proactive or suitable actions to address the accompanying repercussions, specifically water and sanitation difficulties. This paper therefore seeks to investigate the effect of inadequate access to potable water on the residents in the Wa Municipality in Ghana.

\section{REVIEW OF LITERATURE}

The World Water Development Report (WWDR) of the United Nations (UN) for 2021 has offered an update on current trends in clean water availability as well as future expectations. Water security, defined as a population's ability to ensure long-term access to enough quantities of water of acceptable quality, is already in jeopardy for many, and the issue is only going to get worse in the next decades. In today's world of 7.7 billion people, clean water scarcity is a big issue. By 2050, the world population will have risen by 22 to 34 percent to 9.4 to 10.2 billion people, putting a pressure on the water infrastructure. Uneven population increase in different locations, which is unconnected to local resources, will exacerbate the burden. The majority of this population expansion will occur in poor nations, first in Africa and subsequently in Asia, where clean water scarcity is already a serious concern, according to the World Health Organization and UNICEF (2006). The United Nations World Water Development Report, Leaving No One Behind, was released on March 19, 2019, during the 40th session of the United Nations Human Rights Council (UNHRC) and in conjunction with World Water Day. It demonstrates how improvements in water resource management and access to water supply and sanitation services are critical to addressing various social and economic inequities, as well as achieving sustainable development goals (Bahri, 2012).

International human rights law requires states to aim toward universal access to water and sanitation for all, without discrimination, with the most vulnerable people receiving priority. Water and sanitation services must be available, physically accessible, equitably inexpensive, safe, and culturally acceptable in order to fulfill human rights to water and sanitation (Jérémie, 2006; Helena, 2009). According to WHO and UNICEF (2015), 26.3 percent of the world's population did not have access to a better water source on their premises and had to go outside to obtain water. Given the Sustainable Development Goals (SDGs) goal of universal and equitable access (i.e., 100 percent) to water by 2030 , it is critical to assess the influence of collection difficulty, whether in terms of time or distance, on this target. The globe is facing an invisible water quality crisis that is robbing badly polluted places of one-third of their potential economic growth and endangering human and environmental well-being. Lack of access to water inhibits economic growth by one-third (Loc, 2012). It demands that these threats, which affect both rich and developing countries, be addressed immediately at the global, national, and local levels. Healthy water is a critical component of economic development. In many countries, declining water quality is stifling economic progress, affecting health, lowering food supply, and intensifying poverty. Report of the United Nations Millennium Summit (2000).

According to WHO/UNICEF (2017), over half of the global population or 4.2 billion people lack access to satisfactory water supply. World Health Organization (WHO) and UNICEF provide the United Nations systems monitoring of progress on Millennium Development Goal's target 10. They jointly define safe drinking water from four different perspectives. To begin, they describe drinking water as water used in the home for cooking, drinking, and personal hygiene. The second definition emphasis the distance of the source of the water which should not 
exceed 1 kilometer away from its place of use and it is possible to reliably obtain at least 20 liters per member of a household per day. The third definition covers the microbial chemical and physical characteristics that meant WHO guidelines or national standards on drinking water quality. The final definition has to do with the proportion of people using improved drinking water sources such as household connection, public standpipe, borehole, protected dug well, protected spring, or rainwater (Clasen \& Sugden, 2009).

For Africa's rapidly rising population, delivering safe, accessible water is a specific problem. Despite the continent's rich water resources, notably in the Congo Basin, majority of African countries lack access to clean drinking water, owing to poverty and violent conflicts (UNICEF, 2006). Cholera and other water-borne diseases have been common, wreaking havoc on the health and well-being of tens of thousands of people. Furthermore, also in Africa, in which fresh water and sanitation facilities are accessible, a lack of hygiene information continues to lead to water-related disease outbreaks (Thebaut, 2005). Adequate access to clean water is a vital component of obtaining high quality care, which

Table 1. Standards for Potable Water

\begin{tabular}{ll}
\hline Arsenic & $\mathbf{0 . 0 5}$ \\
\hline Calcium & 0.005 \\
Cyanide & 0.05 \\
Fluoride & 1.5 \\
Lead & 0.05 \\
Mercury & 0.001 \\
Nitrate & 10 \\
Selenium & 0.1 \\
Benzene & 0.03 \\
DDT & 1 \\
Chloroform & 30
\end{tabular}

Source: World Health Organization, 2013

Potable water is defined as water that meets a certain quality level and is intended for human consumption. Over 95 percent of the water delivered to small towns and settlements for residential use comes from groundwater sources. Nevertheless, significant amounts of minerals, particularly metal elements such as iron and manganese, have been identified as a barrier restricting the degree to which these resources may be tapped in most of these groundwater sources. supports economic growth and long-term poverty alleviation. In particular improvement in adequate access to safe drinking water reduces women's workload and frees them to participate actively in economic development which is a precondition for attaining MDG 3 (empowering of women) World Bank Report on Water (2019). A research gap is identified after carefully examining related literature on the study, this research aims at bridging the knowledge gap and advance the literature on the access to potable drinking water.

\subsection{Diverse Views about Water}

People all over the world have diverse views about water. Water is an essential ingredient of life and its supply is constant and beyond the scope of humans to increase, although humans can affect its quality and utility (Getis and Getis, 2005). Some view potable water as free or public good while others see it as private or economic good. Since potable water is seen as an economic good in some societies, people who cannot afford to buy the water resort to the use of streams, wells and other unhygienic sources of water. 
human purpose or need (Kpieta and Laari, 2014; Shedrack \& Nayebare, 2014).

\subsection{Potable Water Accessibility}

Because access to safe drinking water is regulated by distinct countries, definitions vary significantly. Apart from country-specific definitions, access to safe water can also be "determined by the number of individuals who have a decent method of obtaining a sufficient amount of clean water, expressed as a share of the total population." It means that household members do not have to spend a lot of time each day gathering water in rural areas." In this research, physical, technical and economic access to potable water will be considered. Ghana statistical service (2005) had it that, the Upper West Region had $63.9 \%$ of the populace who have access to potable water. This is made up of $15.1 \%$ pipe borne water and $47.8 \%$ of boreholes. The remaining depends on wells, streams and other water sources. It has been estimated by the International Water and Sanitation Decade that, about $63 \%$ of Ghana's population had access to potable water supply. Out of this $93 \%$ were urban dwellers and $50 \%$ rural inhabitants. However, various types of access will influence allocation, design, the use and consequently the impact and distribution of benefits of a new water supply system.

\subsubsection{Physical Accessibility}

Physical access to potable water comes into existence as a result of the fact of difference in spatial distribution and spatial differentiation in settlement. Geographic factors therefore are the main phenomena underlying physical access. Clasen and Cairncross (2004) has indicated that "great differences may be found in water collection distance and time needed to cover this distance".

\subsubsection{Technical Accessibility}

It deals with the technological aspect of the potable water supply system. When the technology does not yield its expected results in terms of efficiency, acceptability of the technology and its availability to the beneficiaries, it influences accessibility (Bahri, 2012; Ghana Water Company Limited, 2009).

\subsubsection{Economic Accessibility}

The issue of economic access to social services such as water has to do with income levels and the cost of water (Chaplin, 1999). These expenses are incurred as a result of individuals and families wasting significant energy and time, particularly as a result of treatment costs and lost productivity in man hours due to water and sanitation-related diseases. These squandered resources should be put to better use in areas like childcare, farming, and education.
Accelerated water and sanitation provision to enhance access to these facilities will thereby improve Ghanaians' health, increase productivity, and reduce poverty (Ghana Statistical Service, 2005). According to Clasen and Cairncross (2004), the fact that a water system is established in a community does not necessarily guarantee access to potable water by all members of the community.

In 2010 , about $84 \%$ of the global population which constituted 6.74 billion people had access to pipe water supply through house connection or to an improved water source through other means than house, including stand pipes, protected springs and wells. However, (UN 2021), further stated that about $14 \%$ (884 million) people did not have access to an improved water source and had to use unprotected wells and springs, canals, lakes or rivers for their water need. In most rural and many urban areas of developing countries, basic infrastructure development requires that obtaining drinking water is typically time consuming and complicated. All available sources, such as wells, lakes, streams, and even canals, will almost certainly be used. The poor are usually denied access to essential utilities like as piped water, sewage, and power, and are at risk of disasters such as fire outbreak, flooding, and infectious diseases. Residents in squatter colonies typically purchase water from peddlers or obtain it from a public drain pipe or well. The constant lifting and transporting of endless containers of water is exhausting and often harmful to one's health, whereas the product delivered, from whatever source is most handy, and may be of questionable value (Chaplin, 1999).

In Ghana for instance, there is currently a vast backlog in the provision of potable water in small towns and rural areas. The lack of access to potable water and poor sanitation contributes to $70 \%$ of the diseases in Ghana (Cooperative Housing Foundation International, 2010). In Ghana, approximately $40 \%$ of homes have access to piped water. Around $41 \%$ of people use well water, while $16 \%$ rely on natural sources for their drinking water. Water tanker services, water vendors, sachet/bottled water, and other sources are available to the remaining $4 \%$ of households. In metropolitan regions, approximately 73 percent of homes have access to piped water, however the source is usually from outside the home. In metropolitan areas, a large percentage of families (16\%) have accessibility to well water, while $11 \%$ have lots of natural and other sources (Clasen and Cairncross, 2004). Also in relation to Northern Ghana, Bacho (2001) stated that the scanty and seasonal nature of rainfall has a significant implication for all year round water accessibility for both economic and household consumption. 


\subsection{Water and its Health implication}

Because the development and management of water resources has important health implications, access to safe drinking water and basic sanitation can have a significant positive impact on human health. Water investment is a cost-effective and efficient strategy to tackle water-borne diseases. Due to financial limits and a scarcity of educated health workers in most developing nations, health needs must be prioritized by the international health community (Clasen, 2006). In Ghana, it is believed that lack of clean water and sanitation is responsible for $70 \%$ of all infections. Because the majority of Ghanaians do not have access to piped water, this is the case. Only $41 \%$ of Ghanaians have access to a piped water supply. Because of a lack of drinkable water and sanitation services, the majority of people in rural and urban regions are vulnerable to disease. For example, over $34 \%$ of rural residents rely on untreated water from streams, rivers, and other natural sources for drinking water. In Ghana, poor water and sanitation conditions have resulted in a high incidence of sanitation and water-related diseases. Malaria, for example, was predicted to account for 44 percent of all outpatient visits to Ghanaian health institutions in 2002. Malaria infections, on the other hand, are spread by mosquitoes, which are aided by poor sanitation and drainage. On the other hand, skin diseases, diarrheal diseases, acute eye infections, cholera and dysentery, trachoma, typhoid and infectious hepatitis, and scabies are projected to account for $12 \%$ of all visits to health institutions (Ghana Water Company Limited, 2009).

Two international groups focusing on water and poverty, Water Aid and Tearfund18, for example, feel that global efforts to eliminate poverty would fail if poor sanitation is not addressed promptly. It's no surprise, then, that access to safe drinking water and improved sanitation systems has been identified as one of the Millennium Development Goals' most important objectives by both international and local organizations such as the New Partnership for African Development (NEPAD), The Ghana Poverty Reduction Strategy and the World Health Organization have both mandated that all member countries take steps to ensure long-term access to safe and adequate clean water supply and sanitation, particularly for the poor. The Millennium Development Goals also recommend that the proportion of the population without access to potable water be cut in half by 2015. (Population and Housing Census, 2010). Accumulated evidence from various researchers on water and sanitation reveals that there is a strong correlation between access to potable water and health. No wonder the WHO estimated that $10 \%$ of global disease burden could be prevented with safe drinking water.

\section{STUDY MUNICIPALITY}

Wa Municipality is one of the eleven Districts/Municipalities that make up the Upper West Region of Ghana. It was elevated from Wa District in 2004 with Legislative Instrument (LI) 1800, as part of the centralization process that began in 1988. The Assembly performs deliberative, legislative, and executive powers in the Municipality under section 10 of the Local Government Act 1993 (Act 426). Wa Municipality is bordered on the north by Nadowli District, on the east by Wa East District, and on the south by Wa District. It is located between the latitudes of $1^{\circ} 40^{\prime} \mathrm{N}$ and $2045^{\prime} \mathrm{N}$, and the longitudes of $9^{\circ} 32^{\prime} \mathrm{W}$ and $10^{\circ} 20^{\prime} \mathrm{W}$. Wa Municipality's capital is Wa, which also acts as the Upper West Region's regional capital. It covers around 579.86 square kilometers, or about 6.4 percent of the Region's land area. The Assembly is entrusted with enabling the implementation of national policies as the highest administrative and political body in the country.

\section{METHODOLOGY}

The data collection and analysis methodology used is a blend of qualitative and quantitative methodologies. Creswell's point of view (2009). Combining quantitative and qualitative data analysis approaches goes a long way toward balancing the strengths and weaknesses of the two, as well as enhancing validity and reliability. Based on the home population, the study used simple random sampling to select 520 respondents from the Municipality. Based on the 2010 Ghanaian Population and Housing Census numbers, the residential areas polled during the study were divided into five zones: Busa, Kpong, Wa, Charia, and Kperisi, with households picked systematically with probability proportional to the household population of each zoned region. Purposive sampling was used once again to obtain information from major organizations such as the Ghana Water Company and some Municipal Assembly Departments deemed pertinent to the study's goal. The researchers employed structured questionnaires and interviews to interview family heads or representatives, as well as to obtain information from major institutions involved in the Municipality's water delivery services. Secondary data was gathered from the field, publications, papers, and major entities within the Municipality that were deemed significant for the study's goal. The status of water supply services in the Municipality, issues related with the provision and supply of potable water, and the effects of limited access to potable water supply in the Municipality are among the data acquired. The distance and time it takes to get to water; the average time spent waiting at water sources; and a slew of other factors. The quantitative data was organized using the Statistical Package for 
Social Sciences (SPSS), version 23, and Microsoft Excel, which was displayed as frequency tables, pie charts, and bar graphs. For the analysis, the rationalized data were utilized to produce measures of core tendencies. After carefully reviewing the data, the researchers came up with policy implications for the statistics obtained by SPSS and Microsoft Excel. Making thorough assertions and analytical descriptions regarding the statements provided by the respondents during the data gathering procedure was part of the qualitative data analysis. Water accessibility in the Municipality was assessed using a variety of criteria, including adequacy, regularity, reliability, affordability, and distance.

\begin{abstract}
ANALYSIS AND DISCUSSIONS
Household Water Supply Source in the Municipality

Water is an essential resource for the global economy and also a precondition for human, plant and animal life, as there can be no health and wellbeing stability without a reliable and sufficient supply of drinkable water (Wilson, 1998; Volker, 2007). Water is not only an important ecological aspect for all forms of life, but it also plays a significant role in human socioeconomic development. Access to safe drinking water is a severe problem in most Ghanaian cities and rural areas, and Wa municipal is no exception.
\end{abstract}

Figure 1.1 Distribution of Household Water Supply Source in the Municipality

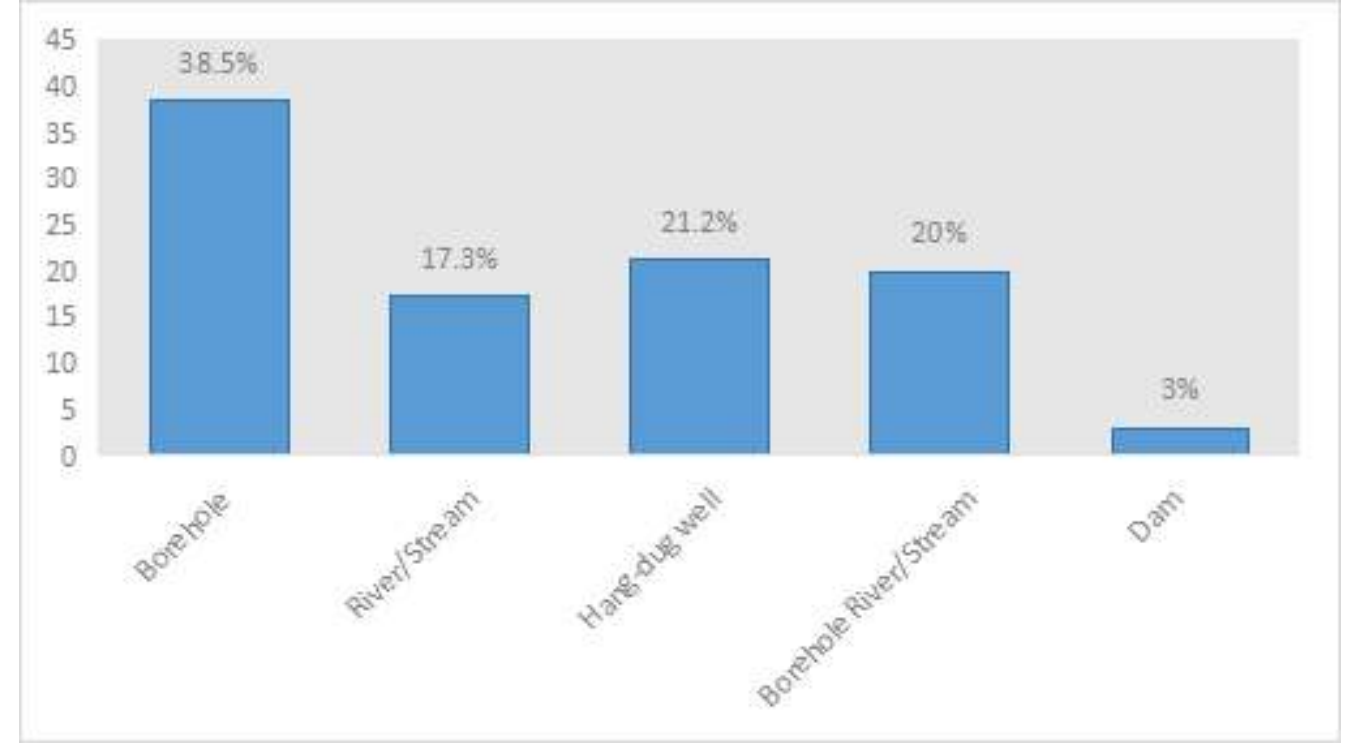

From figure 1.1, it is clear that out of the 520 respondents $38.5 \%$ have access to borehole as their source of water supply, $17.3 \%$ of them have stream as their source of water, hand dug well serves $21.2 \%$ of them, $20 \%$ respondents have access to both Bore hole and River/streams as their sources of water and $3 \%$ of the respondents fetch from the available Dams in the municipality.

\section{Distance Covered in Search for Potable Water}

It can be determined whether a facility's accessibility is high, medium, or low. That instance, within a country, region, or even a neighborhood, users of a certain facility may have high, medium, or low accessibility. According to the Cooperative Housing Foundation [CHF] International (2010), accessibility is high when users of a facility are within a given reasonable travel time of the facility or service in question; on the other hand, accessibility is low when users are out of reach of the facility or service in question within the given travel time. It is consequently critical that certain levels of accessibility be prioritized over the facility's simple availability or existence in a given location. The physical and economic components of water accessibility are intertwined. From the data gathered it was found out that distance covered to access water in the Wa municipality is also a problem since the available functioning boreholes in the Municipality are not accessible to some residents considering the distance they cover before fetching from the available boreholes. The 2019 database for Community Water and Sanitation for the Upper West Region also revealed that some residents are locational disadvantage when it comes to accessibility and utilization of potable water in the Wa municipality, by considering their dwelling places and where the available boreholes are situated is quite unusual. 
It can therefore be said that the residents of these geographical areas have just become victims of water related diseases due to poor location factor, this supports Clasen and Sugden (2009) and Bahri (2012) who argued that water covers three quarters of the earth, yet it is classified as a scarce resource in this world since $1 \%$ of the usable fresh water is available for human daily use.

Table 1.2 Distances Covered in Search for Potable Water

\begin{tabular}{|c|c|c|}
\hline Distance in Kilometers & Number of Respondents & Percentages (\%) \\
\hline $0-1 \mathrm{~km}$ & 160 & 30.8 \\
\hline $2-3 \mathrm{~km}$ & 240 & 46.2 \\
\hline $4-5 \mathrm{~km}$ & 86 & 16.5 \\
\hline $5 \mathrm{~km}+$ & 34 & 6.5 \\
\hline
\end{tabular}

In 2009, the Ghana Water Company Limited (GWCL) stated that in the case of Ghana, if the optimum circumstance of targeting yard associations for all households is not accomplished, the maximum distance a person must travel to access water in an accidental settlement pattern should not exceed 1 kilometer meters. However, the current reality in the Wa Municipality found that just 30.8 percent of the selected houses were within 1 (one) kilometer of the minimal travel distance.

As represented in Table $1.369 .2 \%$ of the respondents covered a distance more than the standard distance of $1 \mathrm{~km}$ stipulated by World Health Organization and Ghana Water Company Limited (GWCL) in search for potable water in the Wa municipality

\section{Time Taken in Search for Potable Water}

In determining the physical dimension of water accessibility, the amount of time spent gathering water is critical. The United Nations (2006) stated that collection time should not exceed thirty (30) minutes for ease of physical access to water supply. In the Wa municipality, however, the time spent bringing water exceeds the UN guideline time. While $40 \%$ of the households studied arrived within the standard time restriction of thirty (30) minutes, $23 \%$ took between thirty and fifty-nine minutes to retrieve water. Again, 36.5 percent of the households surveyed spent 1 (one) hour or more fetching water.

Time is an important factor in accessing potable water in Wa municipality because most of the residents are engage in agricultural productivity and as such spending considerable time to queue on the available boreholes to assess water, they may prefer fetching from the nearby streams in order to save time for their agricultural productivity. However, these alternatives sources such as the dams, ponds and rivers are polluted and as such associated with health risks and challenges (Kpieta and Laari, 2014). The study, however, revealed that the consequences of the time spent and distance traveled to acquire water in the Municipality were largely felt by children and women, owing to the fact that in Ghana, water collection is seen as the unique responsibility of children and women. This information backs up the assumption that when water availability is limited, children and women are the ones who suffer the most (Graham et al., 2016). In a study of the causes of children arriving late to school in the Municipality, it was discovered that water collection time accounted for 62 percent of all documented excuses. Consequently, it was estimated that roughly $40 \%$ of the affected children's academic performance had been harmed. 
Figure 1.2 Time Taken in Search for Potable Water

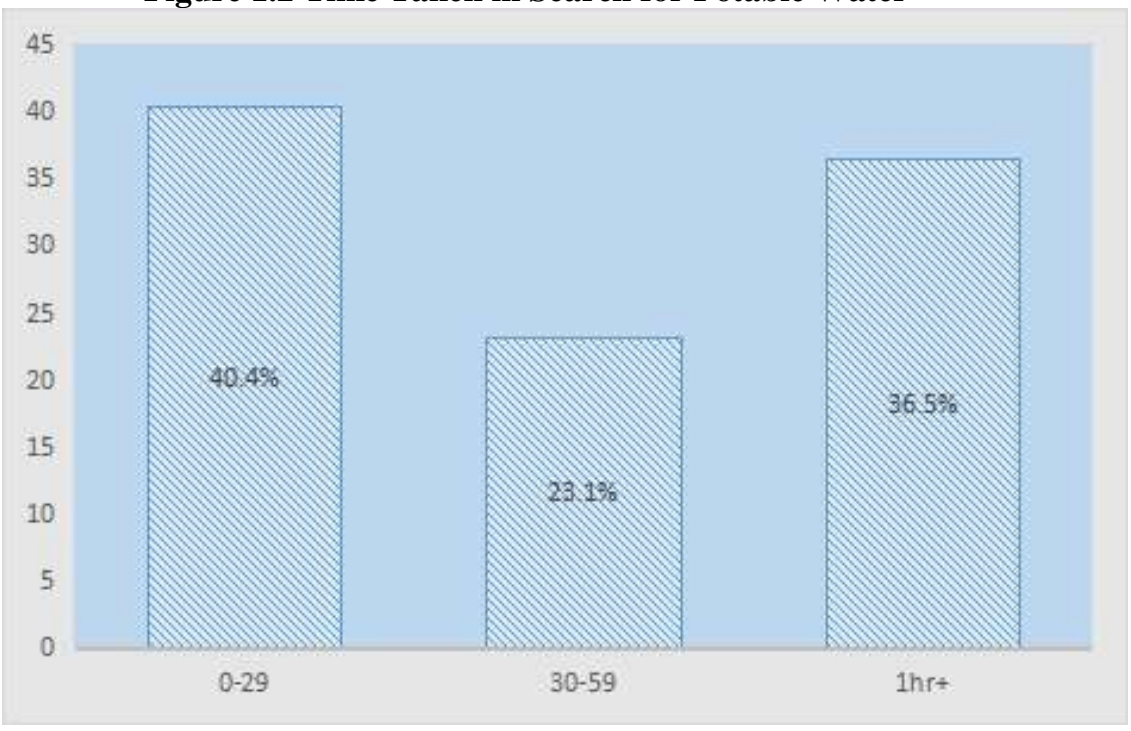

Shistosomiasis is the ailment that afflicts them the most frequently, according to both the household head responses and the various discussants. According to figure 1.3, shistosomiasis was the leading disease burden throughout the year for about
$55 \%$ of respondents. The United Nations World Water Development Report (2019) verified this, citing shistosomiasis as the most prevalent of the three diseases in the municipality.

\section{Figure 1.3 Spatial Variation of Disease Burden on Households}

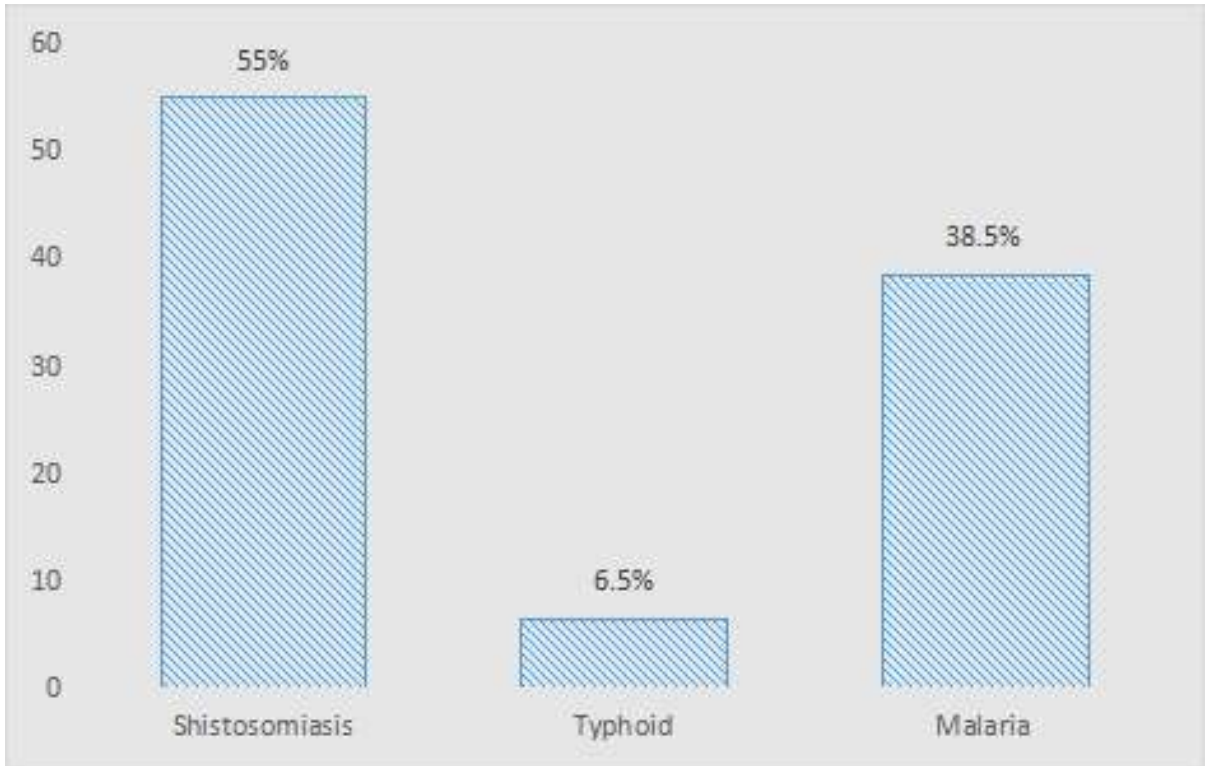

As represented in figure 1.3, shistosomiasis is the top disease among the various diseases in the study area which recorded $55 \%$ out of the total disease burden in the community followed by malaria which also recorded $38.5 \%$ and typhoid recorded $6.5 \%$ which is the least among the three types of disease burden in the study area.
Age Distribution of people who suffer most from Water Related Diseases in the Wa Municipality

Age is an important factor in determining ones susceptibility level to a particular type of disease due to the differences in the immune systems of each year group of people. However, children are susceptible to water related diseases in general due to the fact that 
their immune systems are not mature enough to fight the disease causing agents and the various disease vectors as compare to the immune systems of adults.
The various year groups and their corresponding water related disease burdens in the Wa Municipality are discussed in detail in figure 1.4

\section{Figure 1.4 Age Distribution of Respondents who Suffer from Water Related Diseases in the Wa Municipality}

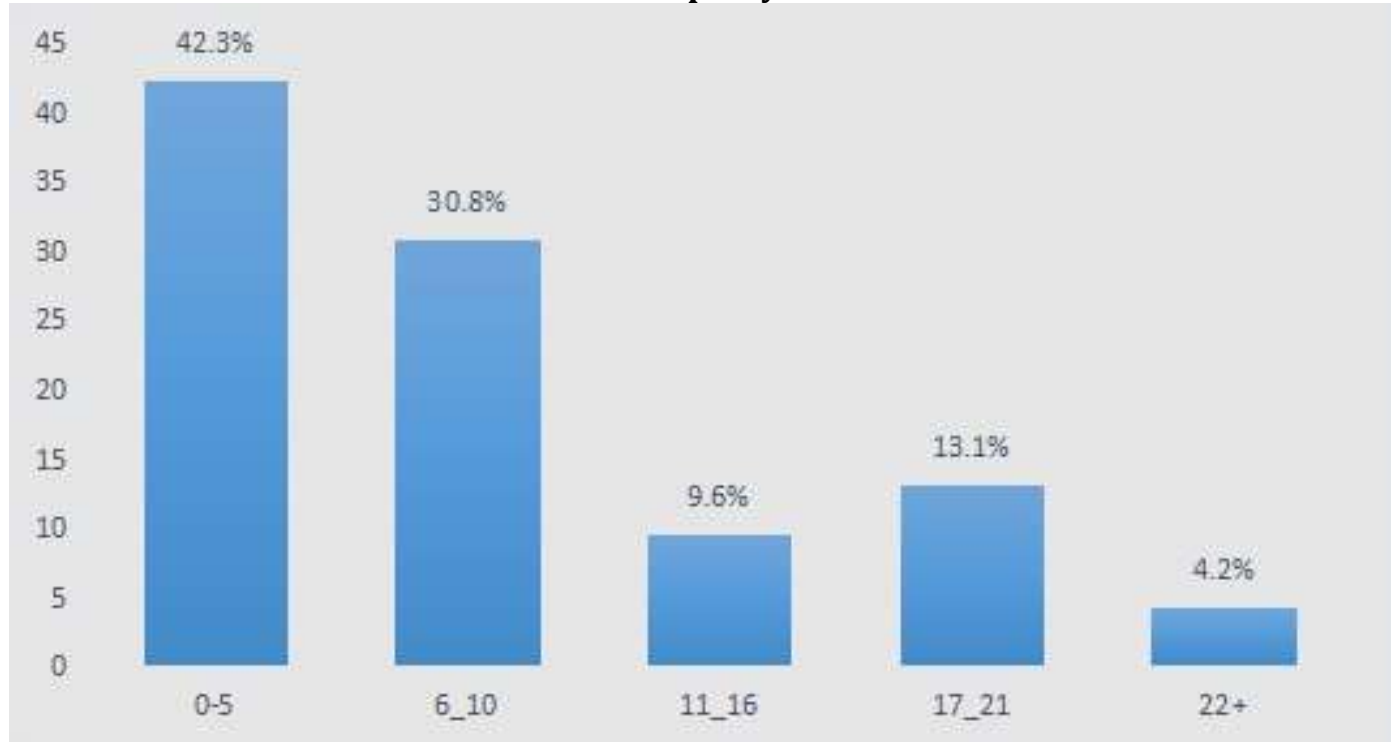

As shown in figure 1.4, it is clear that $42.3 \%$ of the residents who suffer most from water related diseases in the community are between the ages of 0 $-5,30.8 \%$ are between the ages of 6-10years, $9.6 \%$ are between the ages of $17-21$ years, $13.1 \%$ are between the ages of 11-16years and $4.2 \%$ are between the ages of 22 years and above.

\section{Relationship between Access to Potable Water and the Health of the People in the Wa Municipality}

Water is essential in all parts of existence, as evidenced by human societies' sociocultural and economic activities. Water's value is best understood in dry and semi-arid regions, when it takes considerable effort to obtain it for both socioeconomic and home purposes (De Albuquerque, 2010). There is a direct link between access to potable water and people's health, because the spread and outbreak of water-related diseases is limited in areas with easy access to potable water, as opposed to the rampant outbreak and spread of health-related diseases in places and communities without access to potable water. The household head respondents, staff of Wa regional hospital and the various discussants indicated that about $67 . \%$ of the people in the municipality suffer from water related diseases such as shistosomiasis, typhoid and cholera.

\section{Management of Potable Water}

The study sought to find out the respondents views about community participation in the management of potable water and its associated effects on them. The study sought to gather information on the management of water in the study area because there could be numerous forms of potable water facilities in a community but if the community members do not claim ownership of them and adhere to their management through regular maintenance of worn-out parts and regular cleaning of the facility's environment there could still be inadequate potable water supply in such community since the rate of depreciation and break downs of those water facilities in such community will be high and very frequent due to ineffective management. 
Fig. 1,5 Respondents Participation in the Management of Water in the Wa Municipal

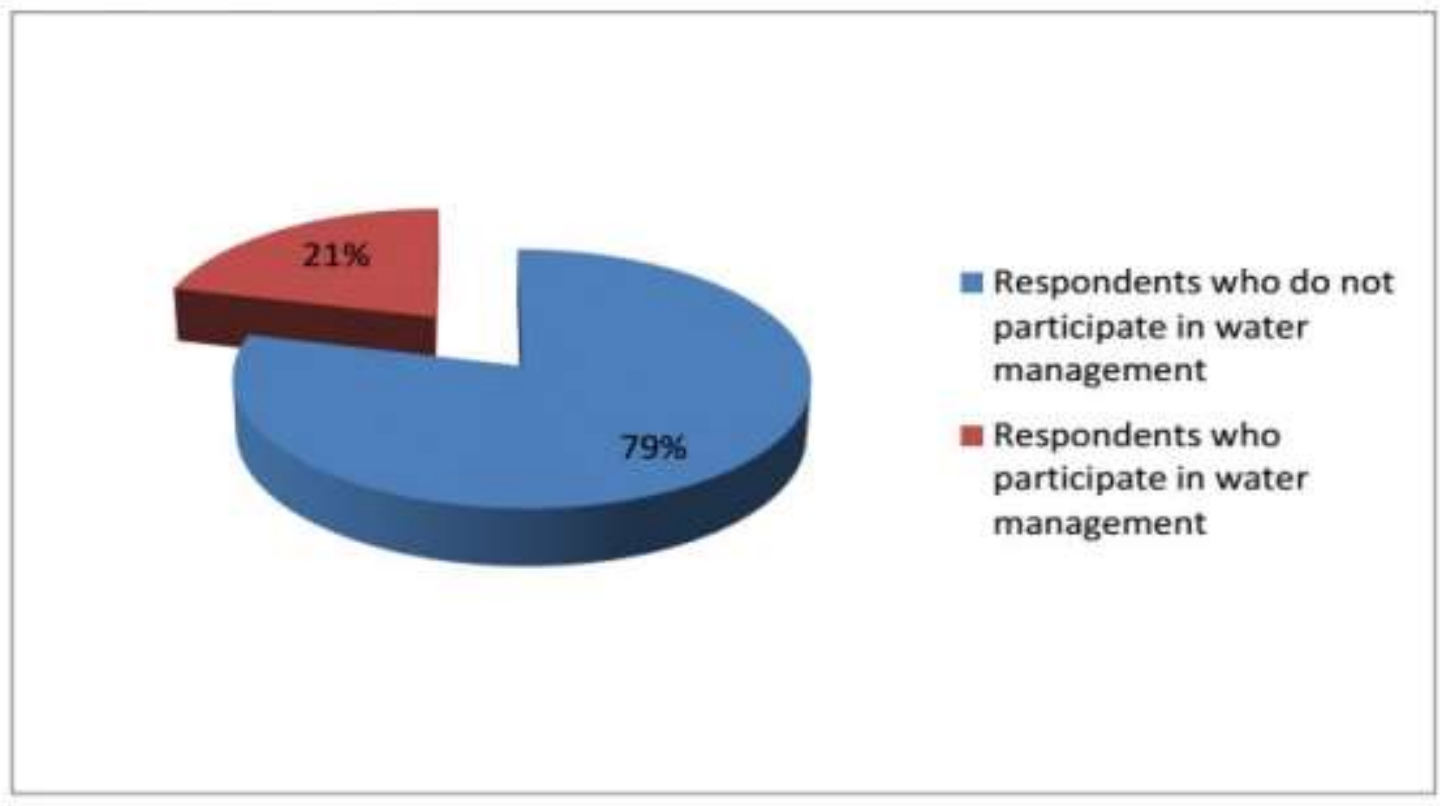

As shown in fig1.5, it is clear that $79 \%$ of the total number of respondents had no idea or knowledge about community participation in the management of potable water hence they do not participate in the community water management. However, $21 \%$ had an idea about water management and do not actually participate. Again, it could be deduced that, majority of the respondents do not participate in the management of water in the $\mathrm{Wa}$ municipality which is attributed to the inadequate potable water supply.

\section{Reason for the Ineffective Community Participation in the Management of Potable Water.}

Numerous factors contribute to ineffective community participation in the management of potable water. These factors however, vary from community to community due to different sociopolitical, economic and cultural conditions.

Through the household head respondents and the various discussants it was brought to light that the ineffective community participation in the management of potable water in the Wa Municipality are as a result of the following factors. In the first place, out of the 520 respondents that the researchers interviewed 349 of them representing $67.1 \%$ attributed their ineffective participation in the management of potable water in Wa municipality to the fact that "water is a free gift of nature", the reason being that God gave water so there should not be any reason why they should pay or turn it into economic good before getting it.
Finally, 23\% of the respondents also attributed their ineffective participation in the management of potable water to poverty. According to them, due to low income they are unable to contribute any money to service the facilities. About $85 \%$ of the farmers said they grow to feed their immediate families -thus subsistence basis, so they have no income for issues regarding water.

It can therefore be concluded that residents of Wa municipal have become victims of numerous water related diseases due to the inadequate supply of potable water in the municipality.

\section{SUMMARY OF MAJOR FINDINGS}

The empirical core of this study comprises detailed enquiries on the causes, effects, existing mechanisms and remedies of inadequate potable water supply in the in the Wa Municipality.

Major findings from the field of research revealed that inadequate potable water supply has adverse effects on the society and hence strategic mechanisms for solving the problem could serve as a gate way for ensuring socio-economic growth and development in the study area and the world at large. Again, the study revealed that there is a direct correlation between access to potable water and people health since the spread and outbreak of water related diseases in areas where there are easily access to potable water is limited as compared to the rampant outbreak and spreading of health related diseases in places and communities without access to potable water.

Furthermore, the analysis indicated that the Municipality's water accessibility is severely 
hampered on both an economic and physical level. The main institution, Ghana Water Company Limited, which is responsible for providing potable water to Municipal residents, does not have the production capacity to meet the average daily water demand or requirement of 50 to 100 litres per household per day, resulting in only half of the daily water needs being met. It is impossible to overestimate the importance of mankind having access to adequate quantities and quality of drinking water. However, the investigation indicated that in the Municipality, obtaining adequate quantities and quality of water is quite difficult. While the average household daily water requirements of 50 to 100 litres set by the United Nations Children's Fund (2001) and the United Nations in 2006 were not reached, water contamination was a major concern, as was the high cost of water. The study found that all of the tested homes in the Municipality spent between $7 \%$ and $10 \%$ of their monthly incomes for water, greatly exceeding the United Nations' 2006 recommendation of $3 \%$ of household income for water, with low-income households being the hardest hit. This condition not only goes against globally acknowledged indicators, but it also makes it difficult to satisfy other similarly basic human needs. Apart from the Ghana Water Company Limited's incapacity to supply suitable water volumes in the Municipality, the Assembly had also failed to determine the market paid on water by non-governmental commercial water vendors, or make any endeavor to enhance water supply in the Municipality.

\section{CONCLUSION}

Because of the increased public health risk linked with the usage of dirty water sources such as streams, dams, and rivers by inhabitants of Wa city in Ghana's Upper West Region, inadequate access to potable water is becoming an issue that requires immediate action from all stakeholders. Water stress in the region exacerbates the situation during the region's seven-month dry season, which runs from October to May each year. People consume severely contaminated water from dams, rivers, and streams due to a lack of potable water for domestic use, putting their health at danger. In the municipality, these polluted rivers are also the only source of water for vegetable production and animal watering. Households residing near these sources of water are at a higher risk of contracting infectious and parasitic disorders. The results of this survey show that citing dams and streams in water-stressed communities like $\mathrm{Wa}$ and its surrounding communities in the Upper West Region without sufficient boreholes for households' safe drinking water needs is a recipe for increasing the burden of water-related disease on the people.
The following recommendations were given in light of the study's findings. To begin, substantial attention should be paid to increasing the capacity of water provisioning organizations to fulfill demand. Due to the fact that the Ghana Water Company Limited is unable to meet water demand or requirement in the Municipality as revealed by the study, the Municipal Assembly should try to compliment water production capacity in the Municipality, and the activities of private water operators should be controlled to reduce the high price for water in the municipality, in order to avoid exploitation, and also to protect the concern of consumers. This could be achieved through dialogue with the private water suppliers in the municipality.

Moreover, Community Water and Sanitation Agency (CWSA) in collaboration with Ghana Water Works (GWW) should conduct in-service training and seminars for the residents of the Municipality about the needs, importance and roles of community participation in water management system.

\section{REFERENCES}

1. Bacho Z.L.F (2001a). From a gift of Nature to an Economic Good. Changing the Perceptions and Management of Drinking Water. Spring Research Series, Published by Spring Centre, University of Dortmund. House. Pall Mall. London.

2. Bahri, A. (2012). Integrated Urban Water Management. Stocskholm: Global Water partnership.

3. Chaplin, S. E. (1999). Cities, sewers and poverty: India's politics of sanitation. Environment and Urbanization, 11(1), 145-158. http://dx.doi.org/10.1177/095624789901100123

4. Clasen, F. T., \& Cairncross, S. (2004). Household Water Management: s.l.:Trop. Med. Int.

5. Clasen, T. (2006). Interventions To Improve Water Quality for Preventing Diarrhoea. Cochrane Database Syst. Rev. s.l.:s.n.

6. Clasen, T., \& Sugden, S. (2009). Water and sanitation. In R. Detels, R. Beaglehole, M. A. Lansang, \& M. Gulliford (Eds.), Oxford textbook of public health, Volume 1: the scope of public health (pp. 159-176). Oxford: Oxford University Press.

7. Cooperative Housing Foundation International. (2010). Sekondi-Takoradi Poverty Map. A Guide to Urban Poverty Reduction in SekondiTakoradi. Sekondi-Takoradi: CHF International.

8. De Albuquerque, C. (2010). Report of the Independent Expect on the Issue of Human Rights Obligations Related

9. Catarina de A. (2012). On the Right Track Good Practices in realizing the rights to water and sanitation, UNESCO WWAP

10. Community water and Sanitation database (DiMES 2011) Upper West Region

11. Creswell, J. W. (2009). Research design; Qualitative, quantitative, and mixed methods approaches (3rd ed.). sage publication, Inc. 
12. Graham J., Hirai M. \& Kim S.-S. 2016 An analysis of water collection labor among women and children in 24 sub-Sarahan African countries PLoS One 11 (6), e0155981 Google Scholar Crossref PubMed

13. Getis and Getis, (2005). The Analysis of Spatial Association by Use of Distance Statistics.

14. Ghana Government, (2003). Ghana poverty Reduction Strategy. AN agenda for growth and development. Accra, Ghana: National Development Planning Commission.

15. Ghana Statistical Service (2010). Population and Housing Census Report.

16. Ghana Statistical Service Report - Wa, Upper West Region (2005).

17. Ghana Water Company Limited. (2009). Ghana Water and Sanitation Sector. Performance Report, Accra: Ministry of Water Resources, Works and Housing

18. Helena L. (2009). Children's Book Review of a Fish out of Water, by Helen Palmer illustrated by P. D. Eastman, 1961, Random House

19. Hubbard B, Sarisky J, Gelting R, Baffigo V, Seminario $R$, etal. A community demand driven approach toward sustainable water and sanitation infrastructure development. Int J Hyg Environmental Health, (2011).

20. Jérémie T. (2006) Costing MDG Target 10 on Water Supply and Sanitation: Comparative Analysis, Obstacles and Recommendations. World Water Council

21. Kpieta B. A and Laari B. P (2014). Small-Scale Dams Water Quality and the Possible Health Risk to Users of the Water in the Upper West Region of Ghana

22. Loïc F. (2012). Achieving the MDGs for Water and Sanitation in Africa, Cotonou Snyder (20062011). Report on water project.

23. 2010 Population and Housing Census District Analytical Report Wa Municipality, (2010).

24. Shedrack $R$. Nayebare. (2014). A review of Potable water accessibility and Sustainability issues in developing countries.

25. Thebaut J. Produced and directed by J. Thebaut. Redondo Beach, CA: The Chronicles Group; 2005. Running dry.

26. UNICEF \& WHO (2015), Progress on Sanitation and Drinking Water 2015 Update and MDG Assessment

27. UNICEF \& WHO (2017), Progress on Drinking Water, Sanitation and Hygiene and SDG Baselines.

28. (WHO \& UNICEF, 2006 ;) Global Issues In Water, Sanitation, And Health

29. JMP (Joint Monitoring Programme for Water Supply and Sanitation). Progress on drinking water and sanitation: special focus on sanitation. New York and Geneva (2006).

30. United Nation Human Settlement programme (UN-HABITAT) Water and Sanitation in the World's Cities, Local Action for Global Goals, Earthscan Publication LTD, London. Sterling, VA. (2006).
31. UN (United Nations). World water development report, determining the true value of the blue gold' we need to protect. New York: UNESCO and Earthscan; 2021.

32. The United Nations World Water Development Report, Leaving no one behind, New York: UNESCO and Earthscan; (2019).

33. United Nation Millennium Summit (2000) Report on MDG II.

34. United Nations Children's Fund (UNICEF). (2001). Safe Drinking Water, New York, NY.

35. Volker H. (2007). Children and the Right to Water. Switzerland.

36. Wilson, F.J. (1998). Making Waste Work; A Strategy for Sustainable Development. Int'l Journal of Environmental Science \& Management. Vol. 6(8). 114 -118.

37. World Bank Report on Water (2019). Worsening Water Quality Reducing Economic Growth by a Third in Some Countries.

38. World Health Organisation \& UNICEF. (2006). Meeting the MDG Drinking Water and Sanitation Target: The Urban and Rural Challenge of the Decade. Geneva: WHO Press.

39. World Health Organisation. (2004). Meeting the MDG Drinking Water and A Mid-Term Assessment of Progress; Geneva: 